\title{
As personagens engajadas nos romances $O$ Tempo e o Vento, de Érico Veríssimo, e Levantado do Chão, de José Saramago.
}

\author{
Iraci Lacerda ${ }^{1}$
}

\begin{abstract}
RESUMO: Ao analisar os aspectos semelhantes e diferenciadores do engajamento das personagens a partir das sublevações, revoltas, guerras e revoluções mencionadas, e também da atuação de suas personagens engajadas, observamos a participação das personagens-proprietárias e das personagens-trabalhadoras nas épocas em que se passam as narrativas. Notamos em suas enunciações pontos de vistas que expressam os interesses das respectivas classes sociais e ilustram o desejo de transformação, ou não, da sociedade.
\end{abstract}

ABSTRACT: In analyzing the similarity and differentiating aspects of the political engagement of characters, from the seditions, uprisings, wars, and revolutions mentioned on the narratives, as well as from the performance of engaged characters, one can observe how landlords-characters and workers-characters experienced those periods. In their enunciation we can note points of view which express the interests of the respective social class and illustrate their willing of transforming society or not.

PALAVRAS-CHAVE: Personagem engajada; classes sociais; transformação.

KEYWORDS: Politically engaged character; social class, transformation.

Com o objetivo de analisar os aspectos semelhantes e diferenciadores do engajamento das personagens, observamos a participação das personagens-proprietárias e das personagens-trabalhadoras em sublevações, revoltas, guerras e revoluções (coincidentes nas narrativas: o fim da Monarquia, o início da República até o fim do Estado Novo no Brasil em 1945 e em Portugal 1974).

Esse diálogo entre os romances O Tempo e o Vento e Levantado do Chão, publicados durante o século XX, segue pelos caminhos da história e da política a partir da observação do modo de vida das personagens, do seu posicionamento à determinada ideologia $^{2}$ e das ações que realizam para manter ou negar o modo dominante das relações de produção ${ }^{3}$ em funcionamento nas sociedades em que vivem.

1 Mestranda em Estudos Comparados de Literaturas de Língua Portuguesa, FFLCH-USP. Pesquisa: Personagens engajadas em sociedade de classes: Uma leitura comparativa entre Levantado do Chão de José Saramago, e O Tempo e o Vento, de Érico Veríssimo.

${ }^{2} \mathrm{Na}$ acepção de István Mészáros: “a ideologia não é ilusão nem superstição religiosa de indivíduos malorientados, mas uma forma específica de consciência social, materialmente ancorada e sustentada. Como tal, não pode ser superada nas sociedades de classe. Sua persistência se deve ao fato de ela ser constituída 
Ambas, as narrativas, inicialmente observadas em seus aspectos históricos, ${ }^{4}$ apresentam uma mistura do histórico com o político na medida em que a atividade de algumas personagens centrais passa a ser a de perseguir determinados fins para tais sociedades. Isso levou-nos a refletir sobre a distinção apresentada por Irving Howe, que considera o romance político quando

A idéia de sociedade, distinta das meras obras inquestionadas da sociedade, penetrou na consciência das personagens em todos os seus aspectos profundamente problemáticos, de forma que pode ser observada em seu comportamento, e elas próprias estão geralmente cônscias de alguma lealdade política coerente ou identificação ideológica. Elas pensam em termos de apoiar ou opor-se à sociedade como tal: elas se arregimentam a um ou outro segmento fortificado da sociedade, e fazem isso em nome de e sob a inspiração de uma ideologia. Para ser um romance, deve conter a representação usual de comportamento e sentimento humanos; ainda assim, deve também absorver em seu fluxo de movimento blocos duros e talvez insolúveis da ideologia moderna. O romance trata de sentimentos morais, paixões e emoções; tenta, acima de tudo, capturar a qualidade da experiência concreta. A ideologia, entretanto, é abstrata como deve ser e, portanto provavelmente recalcitrante sempre que seja feita uma tentativa para incorporá-la ao fluxo de impressões sensuais do romance. O conflito é inevitável: o romance tenta confrontar a experiência que é imediata e íntima, enquanto a ideologia é, por natureza, geral e abrangente. Mesmo assim, é precisamente desse conflito que o romance político ganha seu interesse e assume a aura de um drama solene. ${ }^{5}$

Assim, essa identificação ideológica, da qual trata Howe, permitiu-nos identificar na ação das personagens centrais o engajamento político que as levam a apoiar ou a opor-se à sociedade. Este engajamento, observado nas relações entre as personagens protagonistas e

objetivamente (e conseqüentemente reconstituída) como consciência prática inevitável das sociedades de classe, relacionada com a articulação de conjuntos de valores estratégicos rivais que tentam controlar o metabolismo social em todos os seus principais aspectos [...] as ideologias conflitantes de qualquer período histórico constituem a consciência prática necessária em termos da qual as principais classes da sociedade se inter-relacionam e até se confrontam, de modo mais, ou menos, aberto, articulando sua visão da ordem social correta e apropriada como um todo abrangente". O conflito fundamental entre as classes se dá, segundo Mészáros, pela própria estrutura dividida da sociedade que regula as práticas produtivas e distributivas. In: $O$ poder da ideologia. São Paulo: Boitempo, 2004. p. 65.

${ }^{3}$ São relações que se estabelecem entre os proprietários dos meios de produção e os trabalhadores em um dado processo de produção. In: HARNECKER, Marta. Os conceitos elementares do Materialismo Histórico. São Paulo: Global Editora, 1983. p. 53.

4 Observávamos os aspectos históricos considerando a exposição de Jacques Leenhardt sobre as transformações do ponto de vista no $O$ Tempo e o Vento: "O curso da História traz à tona, ao contrário, um fenômeno infinitamente mais complexo: a transformação dos pontos de vista. Para traduzir essa realidade, não é suficiente apenas adicioná-los, temos que mostrar como a história opera modificações nos objetos e nas pessoas portadoras dessas evoluções". "Narrativa e história em O Tempo e o Vento". PESAVENTO, Sandra et al. In: Érico Veríssimo - O Romance da História. São Paulo: Nova Alexandria, 2001. p. 27.

${ }^{5}$ HOWE, Irving. A Política e o Romance. São Paulo: Editora Perspectiva, 1998. p. 7. 
oponentes, ${ }^{6}$ remete-nos ao espaço político, ou seja, o meio ambiente político por onde as personagens circulam ou refletem sobre decisões e de onde partem as propostas de ações políticas.

Como observado por Howe ao se arregimentarem "a um ou outro segmento fortificado da sociedade sob a inspiração de uma ideologia" cada uma das personagens apresenta-se ativa e assume determinadas tarefas neste espaço de acordo com uma ideologia, com um objetivo a ser alcançado e com seu grau de comprometimento ou disposição política, o que revela, em suas várias vozes, formas de ver o mundo e de compreender a realidade para transformá-la ou mantê-la.

As semelhanças, entre as personagens engajadas, estão no ardor e na disposição de seguir adiante fazendo seus próprios caminhos de acordo com suas convicções políticas. Porém, o que mais nos chama à atenção são os aspectos diferenciadores do engajamento.

$\mathrm{O}$ personagem politicamente ativo, existente em ambos os romances aqui comparados, diferencia-se entre os personagens que vendem a força de trabalho ${ }^{7}$ (expresso em Levantado do Chão) e os proprietários dos meios de produção ${ }^{8}$ (expresso em $O$ Tempo e o Vento). Distinguem-se, assim, de acordo com a classe social ${ }^{9}$ que se apresenta em permanente conflito com a classe oponente.

Os protagonistas João Mau-Tempo de Levantado do Chão, que é trabalhador, e Rodrigo Terra Cambará de $O$ Tempo e Vento, que é proprietário, assumem papéis de lideranças organizadas, pensam e agem de forma coletiva. São imprescindíveis para o movimento político. O lugar de onde falam é o da sua classe social e se diferenciam nas propostas que apresentam para a sociedade.

\footnotetext{
${ }^{6}$ SOURIAU, Etienne. Apud: BOURNNEUF, Roland e OUELLET, Real. O Universo do Romance. Coimbra: Livraria Almedina, 1976. p. 199-242. Consideramos, resumidamente, estas funções: Protagonista é a personagem central da narrativa, o sujeito da ação. Oponente é a personagem secundária que coloca obstáculos à ação da personagem protagonista. Adjuvante é a personagem secundária que auxilia a personagem protagonista, na busca de seu objeto.

${ }^{7}$ Entendemos a energia ou a capacidade do trabalhador gasta durante o processo de trabalho e que é vendida ao proprietário dos meios de produção. HARNECKER, 1983, p. 35. Nesta pesquisa, consideramos todos aqueles e aquelas, que assim o faz, em troca de salário. Não só os que executam o trabalho manual, mas a totalidade do trabalho assalariado e ainda os que estão desempregados.

${ }^{8}$ Entendemos por meios de produção todos os instrumentos e meios para se produzir, ou seja, desde os materiais que intervêm diretamente no processo de trabalho até os locais de instalação. HARNECKER, 1983, p. 34.

${ }^{9}$ Consideramos a reflexão de Eric Hobsbawm quando esclarece que classe não define um grupo de pessoas em isolamento, mas um sistema de relações, tanto verticais quanto horizontais. É uma relação de diferença (ou semelhança) e de distância, mas também uma relação qualitativamente diferente de função social, de exploração, de dominação/sujeição. In: Sobre História. São Paulo: Companhia das Letras, 2004. p. 99.
} 
A família Mau-Tempo e a família Terra Cambará compõem classes sociais diferentes e apresentam em Levantado do Chão, o desejo de subverter a ordem e em $O$ Tempo e o Vento o de manter o poder de classe dominante. Esses desejos em ação se chocam com os desejos das classes oponentes de modo que

cada palavra se apresenta como uma arena em miniatura onde se entrecruzam e lutam os valores sociais de orientação contraditória. A palavra revela-se, no momento de sua expressão, como produto da interação viva das forças sociais [...] Classe social e comunidade semiótica não se confundem. Pelo segundo termo entendemos a comunidade que utiliza um único e mesmo código ideológico de comunicação. Assim, classes sociais diferentes servem-se de uma só e mesma língua [...] O signo se torna a arena onde se desenvolve a luta de classes. ${ }^{10}$

Assim, o personagem ativo, em interação com as forças políticas, permite-se assumir, independente da origem de classe, um lugar na arena, entre uma ou outra classe social, de onde partirá a sua palavra-enunciação.

Um outro aspecto necessário de observação é a diferença entre a atuação de João e António Mau-Tempo ou Rodrigo e Toríbio Terra Cambará. António Mau-Tempo e Toríbio Terra Cambará também atuam de forma organizada, mas não são personagens que tomam as principais decisões, geralmente as executam. São imprescindíveis e não representam apenas o auxílio aos protagonistas.

Essa relação, que demonstra uma nítida diferença entre as personagens que pensam e decidem e as que apenas executam o que foi decidido, permite-nos considerar o grau de comprometimento ou disposição política e relacioná-la com a práxis ${ }^{11}$ de cada personagem.

Como são sociedades divididas em classes, em que, obviamente, há uma divisão social do trabalho ${ }^{12}$, cada personagem exerce uma atividade exclusiva no processo de produção, fruto da e que leva à alienação ${ }^{13}$. No espaço político - que apresenta a vivência não passiva no mundo, contrária ao alheamento - essa divisão de tarefas se reproduz.

${ }^{10}$ BAKHTIN, Mikhail. Marxismo e Filosofia da Linguagem. São Paulo: Hucitec, 1997. p. 46 e 66. $8^{\mathrm{a}}$ ed.

${ }^{11}$ Pensamos a práxis como atividade humana transformadora da natureza e da sociedade. Teoria guiando a ação e moldando a atividade do homem em relação consciente. Para este estudo, consideramos a práxis social: "é a atividade de grupos ou classes sociais que leva a transformar a organização e direção da sociedade, ou a realizar certas mudanças mediante a atividade do Estado. Essa forma de práxis é justamente a atividade política.” In: VÁZQUEZ, Adolfo Sánches. Filosofia da Práxis. Rio de Janeiro: Paz e Terra, 1968. p. 201.

${ }_{12}$ É a distribuição das diferentes tarefas que os indivíduos desempenham na sociedade, ideológicas ou políticas, que se realizam em função da situação que têm na estrutura social. HARNECKER, 1983, p. 40.

${ }^{13}$ Neste momento pensamos a alienação em relação ao produto do trabalho: "Se o produto do trabalho não pertence ao trabalhador, mas o enfrenta como uma força estranha, isso só pode acontecer porque pertence a um outro homem que não o trabalhador. Se sua atividade é para ele um tormento, ela deve ser uma fonte de 
É possível localizar entre as personagens as que somente pensam e decidem, mas não executam as tarefas ou "não colocam a mão na massa"; as que somente excutam, mas não pensam e não decidem; as que somente fazem ou pensam oportunistamente e, felizmente, as que têm a sua ação dotada da teoria como entendimento da lógica de funcionamento da sociedade, pensam e agem de forma organizada.

Assim, adotamos, para este trabalho, uma denominação para as personagens considerando suas funções no espaço político a partir da importância dada aos conflitos, ao objetivo a ser alcançado, ao grau de comprometimento ou disposição política e à compreensão da realidade para transformá-la ou mantê-la.

Em ambos os romances, entre as personagens, identificamos o engajado, o atuante, o participante e o tarefeiro. Todos com sua importância:

O engajado, reconhece o seu pertencimento a uma classe. Tem em mente um tipo de sociedade desejada e possui uma práxis coerente com seus ideais. Compartilha das propostas programáticas ou filia-se diretamente a uma organização política. Pensa e age coletivamente como forma de fomentar idéias e ações. Dedica boa parte da vida a testar na prática as suas convicções políticas e as da organização. De acordo com as convicções políticas, podemos dizer que o engajado pode ser "de esquerda" - quando se posiciona a favor da classe que vende a força de trabalho e busca pôr fim a exploração de uma classe sobre a outra - "de direita" - quando se engaja para conservar a sociedade capitalista ${ }^{14}$ e/ou aprimorar os mecanismos de exploração em benefício da classe proprietária - e "de centro", quando reconhece a divisão social ou a injustiça social, mas busca apenas mudanças na distribuição da riqueza como forma amenizar os problemas e de humanizar o sistema capitalista. Em O Tempo de Vento consideramos como um dos engajados "de direita” Rodrigo Terra Cambará. Em Levantado do Chão um dos engajados “de esquerda" é João Mau-Tempo.

O atuante, nem sempre reconhece seu pertencimento a uma classe. Portanto, o lugar de onde fala não é definido. Tem em mente alguns ideais de justiça e toma posições, muitas vezes, ambíguas de acordo com as ocasiões. A práxis também se dá de acordo com a

satisfação e prazer para outro.” MARX, Karl. Manuscritos Econômicos e Filosóficos. Apud: FROMM, Erich. Conceito Marxista do Homem. $7^{\mathrm{a}}$ ed. Rio de Janeiro: Zahar Editores, 1979. p. 98.

14 "Uma sociedade em que o dinheiro é o representante geral da riqueza, em que os meios de produção são produzidos e alienados como mercadorias e em que os trabalhadores, em boa parte, vendem a força de trabalho para sobreviver". In: SINGER, Paul. O capitalismo - sua evolução, sua lógica e sua dinâmica. São Paulo: Moderna, 2001. p. 28. 
situação. Geralmente pensa, decide e até "coloca a mão na massa". No entanto, a participação em alguma organização política, quando ocorre, é temporária. Nos romances, encontramos Pedro Missioneiro, em O Tempo e o Vento, e António Mau-Tempo, em Levantado do Chão.

O participante age de acordo com seu bom senso ou com as ordens. Preocupa-se com as questões que apresentam soluções mais imediatas, geralmente quando relacionadas diretamente a seus interesses pessoais. Geralmente, faz ou pensa oportunistamente. Portanto, nem sempre se integra a alguma organização política, mas está sempre aguardando o aparecimento daquela organização "perfeita" o bastante para compreender, decidir e resolver os problemas mais graves.

Por fim, temos o tarefeiro que, geralmente, se reconhece, às vezes de forma inconsciente, como pertencente à classe que lhe delega as tarefas. Não é responsável por pensar nem decidir, apenas cumpre as determinações. É o que executa as tarefas ou o que “coloca a mão na massa”, e por isso mesmo é muito importante nas ações. A participação em alguma organização ocorre de acordo com as afinidades pessoais ou por interesses financeiros. No romance $O$ Tempo e o Vento, encontramos Fandango.

Além dessas personagens, temos as organizações políticas ou os partidos políticos com seus programas, que representam uma síntese da compreensão comum da realidade, entre os membros, um tipo de sociedade que almeja e expressa os ideais de determinada classe social. Nos romances as personagens engajadas, filiadas a partidos políticos, apresentam-se defensoras de ideais liberais ou socialistas. ${ }^{15}$

Em $O$ Tempo e o Vento, as ações coletivas se dão contra as relações de poder préestabelecidas, ou seja, inicialmente, a família Terra e posteriormente Terra Cambará não aceita o poder de mando dos Amaral, que representam a força conservadora monárquica, e busca (posição majoritária) alterar esta situação assumindo o poder. Este é o limite, assumir

\footnotetext{
${ }^{15}$ Segundo Paul Singer, o liberalismo econômico rejeita a intervenção do Estado no mercado e tem como desdobramento no nível político: "propugna a liberdade do indivíduo, enquanto cidadão, produtor e consumidor, [...] proclama o direito de cada um produzir o que deseja e de comprar e vender em qualquer mercado. Este direito no plano econômico, se conjuga com o direito de livre expressão do pensamento, de reunião e manifestação e de participação. Estes direitos implicam o controle do governo pelos cidadãos ou seus representantes eleitos, cumprindo notar que o direito de votar e ser votado [no século XIX] estava restrito aos indivíduos detentores de um mínimo de propriedade ou renda. Não se supunha que a cidadania se estendesse aos pobres". SINGER, 2001, p. 19. Os ideais socialistas figuram "uma nova sociedade e uma nova política na qual a exploração dos trabalhadores, a dominação política a que estão submetidos e as exclusões sociais e culturais a que são forçados deixem de existir”. In: CHAUÍ, Marilena. Convite à Filosofia. São Paulo: Ática, 2003.
} 
o poder político para reorganizar a sociedade sob as bases da República com a descentralização do poder e o desenvolvimento do modo de produção capitalista. ${ }^{16}$

Já em Levantado do Chão, as ações coletivas iniciam-se com reivindicações econômicas, redução da jornada de trabalho e melhores salários. Numa nítida identificação das diferenças entre trabalhadores e proprietários, deixam de lado o inconformismo e a submissão e buscam a superação do capitalismo, ao questionarem o poder econômico, político e social quando buscam transformar a propriedade privada dos meios de produção em propriedade coletiva, no momento em que assumem as fazendas e tomam a decisão de coletivizar a produção e distribuição.

Notamos que os percursos realizados pelas personagens seguem e levam a caminhos diferentes. A consciência de que a sociedade precisa ser transformada, identificada durante os conflitos entre as classes sociais, é o outro elemento diferenciador. Em um estudo sobre o processo de consciência Mauro Iasi diz:

É na própria constatação de que a sociedade precisa ser transformada que se supera a consciência da reivindicação pela da transformação. $O$ indivíduo transcende o grupo imediato e o vínculo precário com a realidade dada, busca compreender relações que se distanciam no tempo e no espaço, toma como sua a história da classe e do mundo. Passa a conceber um sujeito coletivo e histórico como agente da transformação necessária. ${ }^{17}$

Esse comprometimento com a transformação social - presente no engajamento de alguns personagens, típico da consciência socialista - tem como princípio ser anticapitalista e, como estratégia, chegar a uma sociedade sem classes, ou seja, sem explorados e sem exploradores.

Dessa maneira notamos que, em ambos os romances, o personagem ativo politicamente difere-se quanto à classe social, à práxis e à consciência socialista. Assim, podemos observar que o engajar é muito mais do que a tomada de posição sobre um determinado assunto. É estar politicamente ativo no mundo. É a busca por desvendar as aparências e compreender a essência do funcionamento da sociedade. É a compreensão de que a história da humanidade tem sido pautada por desigualdades que levam a lutas ou disputas. Enfim, ser engajado, “de esquerda”, é estar organizado e agir coletivamente para

\footnotetext{
16 “Caracterizado pela alienação da força de trabalho por indivíduos livres em troca de salários, está claro que ele é incompatível com a escravidão e só adquire significado no Brasil após a abolição da mesma”. SINGER, 2001, p. 67.

${ }^{17}$ IASI, Mauro. As metamorfoses da consciência de classe. São Paulo: Expressão Popular, 2006.
} 
construir algo superior e justo, "de direita" para manter ou aprofundar essas desigualdades, "de centro" para amenizar tal situação.

\section{Referências bibliográficas}

ABDALA JR, Benjamin. Literatura, História e Política. São Paulo: Ática, 1989.

BAKHTIN, Mikhail. Marxismo e Filosofia da Linguagem. São Paulo: Hucitec, 1997.

BOURNNEUF, Roland e OUELLET, Real $O$ Universo do Romance. Coimbra: Livraria Almedina, 1976.

CHAUÍ, Marilena. Convite à Filosofia. São Paulo: Ática, 2003

FROMM, Erich. Conceito Marxista do Homem. $7^{\text {a }}$ ed. Rio de Janeiro: Zahar Editores, 1979.

HARNECKER, Marta. Os conceitos elementares do Materialismo Histórico. São Paulo: Global Editora, 1983.

HOBSBAWM, Eric. Sobre História. São Paulo: Companhia das Letras, 2004

HOWE, Irving. A Politica e o Romance. São Paulo: Editora Perspectiva, 1998.

IASI, Mauro. As metamorfoses da consciência de classe. São Paulo: Expressão Popular, 2006.

SARAMAGO, José. Levantado do Chão. Rio de Janeiro: Editora Record, 1996.

MÉSZÁROS, István. O poder da ideologia. São Paulo: Boitempo, 2004.

PESAVENTO, Sandra et al. Érico Veríssimo - O Romance da História. São Paulo: Nova Alexandria, 2001.

SARAMAGO, José. Levantado do Chão. Rio de Janeiro: Editora Record, 1996.

SINGER, Paul. O capitalismo - sua evolução, sua lógica e sua dinâmica. São Paulo: Moderna, 2001.

VÁZQUEZ, Adolfo Sánches. Filosofia da Práxis. Rio de Janeiro: Paz e Terra, 1968.

VERÍSSIMO, Érico. O Tempo e o Vento. São Paulo: Círculo do Livro, 1962. 